\title{
Adsorção em carvão ativado em pó para remoção de microcistina de água de abastecimento público
}

\author{
Powdered activated carbon adsorption for microcystin removal \\ from public water supply
}

\author{
Carla Cristine Müller \\ Bióloga pela Universidade Federal do Rio Grande do Sul (UFRGS). Mestre em Ecologia pela UFRGS \\ Maria Teresa Raya-Rodriguez \\ Doutora em Ecologia e Recursos Naturais pela Universidade Federal de São Carlos (UFSCar). Química e Professora-associada da UFRGS \\ Luiz Fernando Cybis \\ Doutor em Engenharia Sanitária e Ambiental pela University of Leeds, Inglaterra. \\ Professor, Orientador, Pesquisador e Consultor do Instituto de Pesquisas Hidráulicas (IPH) da UFRGS
}

\begin{abstract}
Resumo
A ocorrência de florações de cianobactérias em mananciais de abastecimento público prejudica a qualidade da água, podendo, inclusive, ocasionar a presença de cianotoxinas. A dificuldade de remover as cianotoxinas da água motivou o presente trabalho, cujo objetivo foi o de avaliar a remoção da cianotoxina microcistina empregando diferentes carvões ativados em pó (CAPs). Os CAPs foram caracterizados quanto ao número de iodo, granulometria, distribuição e volume de poros, além das isotermas de Freundlich. Os resultados mostraram que os CAPs de madeira apresentaram os maiores valores do número de iodo, capacidade máxima adsortiva $\left(\mathrm{q}_{\mathrm{e} \text { máx }}\right)$ e volume de microporos secundários e mesoporos. A adequada caracterização do CAP é uma etapa importante na sua aquisição pelas estações de tratamento de água, pois índices isolados podem não avaliar corretamente o CAP.
\end{abstract}

Palavras-chave: microcistina; isoterma de Freundlich; adsorção; carvão ativado em pó.

\section{Abstract}

The cyanobacterial bloom's occurrence in sources of public supplying harms water quality, even causing cianotoxins presence. The difficulty of the cianotoxins removal from the water has motivated the present work, which objective was to evaluate the removal of the cianotoxin microcystin through the use of different powdered activated carbons (PACs). The PACs were characterized according to its iodine number, granulometry, distribution and volume of pores, besides the Freundlich isotherms. The results showed that the wood PACs presented the highest values of iodine number, maximum adsorptive capacity $\left(q_{\mathrm{e}}\right.$ max $)$ and volume of secondary micropores and mesoporos. The adequate characterization of the PACs is an important stage in its acquisition by the water treatment plants, because isolated indices can not evaluate the PACs correctly.

Keywords: microcystin; Freundlich isotherm; adsoption; powdered activated carbon.

\section{Introdução}

A ocorrência de florações de cianobactérias, em mananciais utilizados para abastecimento público, é cada vez mais frequente. Ambientes aquáticos lênticos continentais de clima tropical, onde as temperaturas são elevadas, parecem estimular seu desenvolvimento, embora ocorram nas mais diversas regiões do mundo, independente do clima (ESTEVES, 1998; HUSZAR et al, 2000). A ocorrência de espécies tóxicas e suas respectivas toxinas já foram encontradas em mananciais brasileiros, de acordo com Azevedo et al (1994),
Jochimsen et al (1998), Lagos et al (1999), Matthiensen, Yunes e Codd (1999), Vieira et al (2005), entre outros. Os gêneros de cianobactérias que se destacam pela sua ampla distribuição, pela sua capacidade potencial de produzir toxinas e pelos efeitos que estas causam em outros organismos do ambiente aquático são Microcystis, Anabaena, Aphanizomenon, Planktothrix, Cylindrospermopsis e Nodularia (CEBALLOS; AZEVEDO; BENDATE, 2006). As florações caracterizam-se pelo crescimento excessivo de microalgas ou cianobactérias, sendo observada a dominância destas nas últimas décadas (AZEVEDO et al, 1994). Elas provocam alteração da cor e sabor da 
água, conferindo aspecto desagradável ao manancial e à água tratada proveniente deste, além da possível produção de toxinas potentes que causam intoxicações agudas ou crônicas, as quais podem ter ação hepática ou neurológica com consequências nem sempre bem conhecidas (BRASIL, 2003; CEBALLOS; AZEVEDO; BENDATE, 2006).

As toxinas são produzidas e armazenadas no interior das células em crescimento ativo das cianobactérias produtoras. A liberação das toxinas para o ambiente, na forma de toxina dissolvida, ocorre com a morte, lise ou senescência das células. A liberação contínua é menos frequente. No ambiente aquático, foram observadas concentrações de toxina extracelular de 0,1 a $10 \mu \mathrm{g} . \mathrm{L}^{-1}$, exceto nos casos de grandes florações. As toxinas extracelulares diluem-se rapidamente pela massa d'água, principalmente quando há mistura da água pela ação de ventos e correntes. Entretanto, a concentração de toxina pode ser muito alta, quando a floração já está na fase de senescência (SIVONEN; JONES, 1999). Isso deve ser observado pelos operadores das estações de tratamento de água (ETA), uma vez que, devido ao risco para a saúde representado pelas toxinas, é fundamental que o processo de tratamento da água remova as células intactas das cianobactérias, removendo, consequentemente, as toxinas. Caso contrário, quando há toxina dissolvida na água a ser tratada, tecnologias específicas deverão ser aplicadas para removê-las.

De acordo com os estudos de Himberg et al (1989), Lambert, Holmes e Hrudey (1996), Chow et al (1999) e Drikas et al (2001), em escala de bancada (jar-teste) e em escala piloto, o tratamento convencional, compreendendo coagulação, floculação, sedimentação, filtração e cloração, é eficiente na remoção das células intactas de cianobactérias e demais microalgas. Entretanto, quando há toxina dissolvida na água, esse tratamento mostra-se ineficiente. Neste caso, outras tecnologias devem ser incorporadas ao processo de tratamento, como adsorção em carvão ativado.

A adsorção utilizando carvão ativado em pó (CAP) tem sido a alternativa adotada mais amplamente pelas ETAs (SNOEYINK, 1990), incluindo as brasileiras. O CAP pode ser utilizado em eventos sazonais, sendo aplicado em ETAs já existentes, sem a necessidade de adaptação e construção de novas instalações (DONATI et al, 1994; BRASIL, 2004; BRASIL; BRANDÃO, 2005).

Em função dessa ampla utilização, é necessário avaliar a capacidade de adsorção do CAP utilizado na ETA, para atender o padrão de potabilidade estabelecido pela Portaria n. 518/2004 do Ministério da Saúde (BRASIL, 2004). Segundo essa portaria, fica estabelecido o valor máximo permitido (VMP) para a cianotoxina microcistina de $1 \mu g . L^{-1}$ na água tratada. Sendo assim, o CAP utilizado deve ser eficiente para garantir esse VMP.

Em função dos problemas de saúde causados pelas cianotoxinas e seguindo o padrão de potabilidade brasileiro, estabelecido pela Portaria $n^{\circ} 518 / 2004$, o objetivo deste trabalho foi caracterizar cinco CAPs produzidos e comercializados no país, de modo a obter o CAP com maior eficiência na remoção da toxina microcistina.

\section{Metodologia}

Para escolher o CAP com maior capacidade de remoção de microcistina, é preciso caracterizá-lo para verificar sua eficiência de remoção. Os CAPs podem ser produzidos a partir de diferentes matériasprimas. No Brasil, utilizam-se madeira, osso, casca de coco, antracito e carvão betuminoso e sub-betuminoso. Dependendo da matériaprima, as características do CAP são distintas. Para a caracterização, foram realizados os ensaios de granulometria e índice do número de iodo, constantes na norma EB-2133 (ASSOCIAÇÃO BRASILEIRA DE NORMAS TÉCNICAS, 1991C), que define as especificações para o fornecimento de carvão ativado pulverizado utilizado no tratamento de água para abastecimento público. Também foram determinados a distribuição e o volume de poros, parâmetros fundamentais para avaliar a eficiência do CAP (SNOEYINK, 1990; COELHO; VAZZOLER, 2005; KURODA et al, 2005; BRANDÃO; SILVA, 2006). Para a determinação da capacidade adsortiva do CAP à microcistina, foram estabelecidas as isotermas de Freundlich para cada CAP estudado. Em função deste ensaio, foi necessário manter, em laboratório, o cultivo de uma cepa tóxica de Microcystis aeruginosa, para obtenção da toxina microcistina. Cabe ressaltar que a toxina utilizada foi proveniente da lise celular, produzindo um extrato contendo microcistina e compostos intracelulares resultantes dessa lise. A seguir, são descritos todos os procedimentos e ensaios realizados.

\section{Cultivo de Microcystis aeruginosa e obtenção de microcistina}

A cepa tóxica da cianobactéria Microcystis aeruginosa, cujo inóculo foi fornecido pelo Laboratório de Ecofisiologia e Toxicologia de Cianobactérias do Instituto de Biofísica Carlos Chagas Filho da Universidade Federal do Rio de Janeiro (LETC-UFRJ), foi cultivada em laboratório em Erlenmeyer de 6 L, em meio de cultura ASM-1, sob aeração, temperatura de $25 \pm 1{ }^{\circ} \mathrm{C}$ e fotoperíodo de 12 horas, com intensidade luminosa de $96 \mu \mathrm{mol}$ de fótons $\mathrm{m}^{-2} \mathrm{~s}^{-1}$, em câmara de germinação (marca Tecnal, modelo Te401). Após atingir concentração de células da ordem de $10^{7}$, a cultura era submetida ao processo de congelamento e descongelamento (repetido três vezes) para promover a lise das células e consequente liberação da microcistina intracelular para o meio (BRASIL; BRANDÃO, 2005; KURODA et al, 2005; AZEVEDO; MAGALHÃES, 2006). Em seguida, o material resultante da lise foi filtrado por meio de três filtros de fibra de vidro, com porosidades diferentes (primeiro filtro: Macherey-Nagel GF-1/poro 1,6 $\mu \mathrm{m}$; segundo filtro: MachereyNagel GF-3/poro 0,6 $\mu \mathrm{m}$; terceiro filtro: Macherey-Nagel GF-5/poro 0,4 $\mu \mathrm{m}$ ), com auxílio de bomba de vácuo, para separação do material em suspensão. Este filtrado, denominado extrato bruto de microcistina, foi homogeneizado e congelado, em alíquotas de $1 \mathrm{~L}$, para utilização nos ensaios das etapas posteriores do trabalho. 


\section{Caracterização dos CAPS}

A Tabela 1 apresenta os CAPs utilizados com sua identificação e material de origem.

- Granulometria: realizado de acordo com a norma MB-3412 (ASSOCIAÇÃO BRASILEIRA DE NORMAS TÉCNICAS, 1991A). O ensaio consiste na passagem, por via úmida, de alíquotas de CAP por meio de três peneiras: ABNT n. 100, n. 200 e n. 325. O resultado é expresso em percentagem de massa de CAP passante por meio de cada peneira.

- Índice do número de iodo: o número de iodo está relacionado à adsorção de moléculas de pequeno peso molecular, sendo utilizado como indicador da capacidade adsortiva do CAP, e também é um dos parâmetros estabelecidos pela norma EB-2133 (ASSOCIAÇÃO BRASILEIRA DE NORMAS TÉCNICAS, 1991C). O ensaio foi realizado segundo a norma MB-3410 (ASSOCIAÇÃO BRASILEIRA DE NORMAS TÉCNICAS, 1991B), sendo que o método baseia-se na obtenção da quantidade, em miligramas, de iodo removido, por meio da adsorção, em 1,0 g de CAP. A quantidade de iodo adsorvida é obtida a partir da medida do residual de iodo após um determinado tempo de contato com o CAP. O resultado é expresso em $\mathrm{mgI}_{2} \cdot \mathrm{gCAP}^{-1}$.

- Distribuição e volume de poros: o material usado na produção do carvão e a forma de ativação produzem CAPs com estrutura interna e distribuição de tamanho de poros distintas, resultando em diferenças nas propriedades adsortivas (DONATI et al, 1994; DI BERNARDO; DANTAS, 2005). Os grãos de carvão ativado apresentam diferentes tipos de poros, classificados de acordo com o diâmetro, como 1) microporo primário, menor que 1,2 $\mathrm{nm}$; 2) microporo secundário, entre 1,2 e $2 \mathrm{~nm}$; 3) mesoporo, entre 2 e $50 \mathrm{~nm}$, e 4) macroporo, maior que $50 \mathrm{~nm}$ (BRANDÃO; SILVA, 2006). A distribuição e o volume de poros são as propriedades mais importantes para avaliar a capacidade de adsorção do CAP, pois a máxima adsorção é proporcional ao tamanho da área superficial dentro dos poros que estão acessíveis para ocorrer a adsorção (DONATI et al, 1994). Os cinco CAPs foram submetidos à análise de distribuição do tamanho dos poros por meio da Isoterma Brunauer, Emmett e Teller (BET), técnica de adsorção de nitrogênio a $77 \mathrm{~K}$. Com essa técnica, também foi possível calcular a área superficial.

\section{Isotermas de Freundlich}

Há muitos modelos matemáticos que procuram descrever a relação entre a quantidade de adsorvato por unidade de adsorvente e a concentração de adsorvato na água. A isoterma do modelo de Freundlich é a mais utilizada, pois, mesmo sendo empírica, descreve com precisão os dados de ensaios de adsorção (DI BERNARDO; DANTAS, 2005). Está baseada na distribuição do adsorvato entre a
Tabela 1 - CAPs utilizados neste estudo

\begin{tabular}{lc} 
Identificação do CAP & Material de origem \\
\hline MAD1 & Madeira \\
MAD2 & Madeira \\
COCO & Casca de coco \\
OSSO & Osso \\
ANTRA & Antracito \\
\hline
\end{tabular}

fase sólida (adsorvente) e a fase líquida (água) no equilíbrio (NG et al, 2002; KURODA et al, 2005).

A Equação de Freundlich apresenta a seguinte forma:

$\mathrm{q}_{\mathrm{e}}=K \cdot \mathrm{C}_{\mathrm{e}}^{1 / n}$

Equação 1

onde:

$\mathrm{q}_{\mathrm{e}}$ é a quantidade de adsorvato por unidade de adsorvente (M. $\left.\mathrm{M}^{-1}\right)$;

$\mathrm{C}_{e}$ é a concentração do adsorvato remanescente em solução, no equilíbrio (M.L-3);

Ke $n$ são coeficientes determinados empiricamente.

Segundo Ng et al (2002), quando os dados da equação são plotados como X-Y, em que y $=\log q_{e}$ e $x=\log C_{e}$, a inclinação da curva é $1 / n$ e a interceptação do eixo Y é log $K$.

$\mathrm{O}$ ensaio da isoterma de Freundlich foi realizado baseado na norma D3860-98 (AMERICAN SOCIETY FOR TESTING AND MATERIALS, 2000), com concentração inicial de toxina da ordem de $100 \mu \mathrm{g} . \mathrm{L}^{-1}$, conduzido à temperatura de $20 \pm 1{ }^{\circ} \mathrm{C}$, com tempo de contato de duas horas, em copos de Becker de 1 L. A toxina utilizada foi proveniente do extrato bruto, obtido por meio da lise da cultura de Microcystis aeruginosa, diluído em água deionizada. Cada recipiente recebeu $500 \mathrm{~mL}$ de amostra homogeneizada e concentrações de CAP de 0 (controle), 5, 10, 20, 50 e 100 mg. L $^{-1}$, mantidas em agitação de 160 rpm, em equipamento de jarros (marca Alfa Tecnoquímica, modelo Alfakit AT700), para manter o CAP em suspensão ao longo do tempo de contato. Após esse tempo, a amostra foi filtrada, com auxílio de bomba de vácuo, em filtro de fibra de vidro Macherey-Nagel GF-5 (poro 0,4 $\mu \mathrm{m}$ ), para remoção do CAP. Uma alíquota de $10 \mathrm{~mL}$ foi coletada para a análise de microcistina. Os resultados foram expressos de forma gráfica, mostrando a quantidade de microcistina adsorvida por unidade de massa de CAP. Os valores do gráfico foram calculados pela Equação 2:

$\mathrm{q}_{\mathrm{e}}=\left(\mathrm{C}_{\mathrm{o}} \mathrm{V}-\mathrm{C}_{\mathrm{e}} \mathrm{V}\right) / \mathrm{M}$

Equação 2

onde:

M: massa de CAP, em mg;

$\mathrm{X}$ : quantidade de microcistina adsorvida, em $\mu \mathrm{g}$;

$\mathrm{C}_{\mathrm{o}}$ : concentração de microcistina inicial, em $\mu g . \mathrm{L}^{-1}$;

$\mathrm{V}$ : volume de amostra, em L. 
No gráfico, o eixo $\mathrm{X}$ representa a concentração residual de microcistina $\left(C_{e}\right)$ e o eixo $\mathrm{Y}, \mathrm{q}_{\mathrm{e}}$, ambas em escala logarítmica. O valor no eixo das ordenadas $\left(q_{e}\right)$ que corresponde a concentração inicial de $C_{\mathrm{o}}$, no eixo das abscissas $\left(C_{\mathrm{e}}\right)$, pode ser obtido por extrapolação da isoterma. Este valor de $\mathrm{q}_{\mathrm{e}}$ representa a quantidade de microcistina adsorvida quando o carvão está em equilíbrio com a concentração remanescente de toxina em solução. Assim, esse valor representa a capacidade máxima adsortiva $\left(q_{e, \text { maxx }}\right)$ do CAP para a microcistina (AMERICAN SOCIETY FOR TESTING AND MATERIALS, 2000).

A concentração de microcistina utilizada nesses experimentos foi elevada, ocorrendo em casos de grandes florações ou quando os organismos se encontram em todas as fases de crescimento (MATTHIENSEN; YUNES; CODD, 1999). No entanto, facilita a análise do processo de remoção por adsorção. O uso de água deionizada permite uma maior adsorção de microcistina pelo CAP do que utilizando água proveniente de um manancial, pois neste há material orgânico competidor pelos sítios de adsorção do CAP. Além disso, os experimentos realizados com água deionizada permitem uma melhor reprodutibilidade e comparações com estudos de outros autores (NG et al, 2002).

\section{Análise de microcistina}

A concentração de toxina contida no extrato bruto, assim como das amostras provenientes das isotermas foi determinada pelo ensaio ELISA (Enzyme-Linked ImmunoSorbent Assay), através do Kit Beacon Microcistina - Placa para determinação de microcistina em água (marca Beacon Analytical Systems Inc.). Em cada ensaio, foram coletados $10 \mathrm{~mL}$ de amostra e congelados em frasco de vidro âmbar, até o momento da realização da análise. A faixa de detecção do ensaio é de $0,1-2,0 \mu \mathrm{g} . \mathrm{L}^{-1}$.

\section{Análise estatística}

A concentração de toxina $(\mu \mathrm{g})$ removida da solução por miligrama de CAP foi determinada por diferença e plotada contra a concentração de toxina residual ( $\mu$ g. $\mathrm{L}^{-1}$ ) (concentração resultante ao final do tempo de contato, isto é, duas horas). Análises de regressão foram

Tabela 2 - Parâmetros estabelecidos pela norma EB-2133 para o fornecimento de carvão ativado pulverizado, utilizado na adsorção de impurezas no tratamento de água para abastecimento público

\begin{tabular}{lc} 
Características & Limites \\
\hline Número de iodo $\left(\mathrm{mg} \mathrm{de}_{2} \cdot \mathrm{g}^{-1}\right)$ & 600 mín. \\
\hline Índice de fenol $\left(\mathrm{g} \cdot \mathrm{L}^{-1}\right)$ & 2,5 máx. \\
\hline Umidade $(\%$ em massa) & 8,0 máx. \\
\hline Massa específica aparente $\left(\mathrm{g} \cdot \mathrm{cm}^{-3}\right)$ & 0,20 a 0,75 \\
\hline Granulometria $(\%$ em massa passante) & \\
\hline Peneira ABNT n. 100 & 99,0 mín. \\
\hline Peneira ABNT n. 200 & 95,0 mín. \\
\hline Peneira ABNT n. 325 & 90,0 mín.
\end{tabular}

realizadas. As isotermas de Freundlich foram construídas na forma linear (Equação 3) e foi avaliado o ajuste $\left(\mathrm{R}^{2}\right)$ dos dados ao modelo.

$\log \mathrm{q}_{\mathrm{e}}=1 / n \log \mathrm{C}_{\mathrm{e}}+\log K \quad$ Equação 3

Os resultados do ensaio do índice do número de iodo foram analisados pela correlação de Pearson (significância $\mathrm{p}<0,05$ ) entre o volume de poros e a capacidade adsortiva do CAP obtida por meio das isotermas de Freundlich ( $K$ e $\mathrm{q}_{e, \text { máx }}$ ).

\section{Resultados e discussão}

Os ensaios de caracterização dos CAPs (granulometria e índice do número de iodo) foram realizados anteriormente à isoterma de Freundlich, que caracteriza o processo adsortivo, pois são de menor complexidade e fornecem os resultados em poucas horas. Estes ensaios são muito utilizados para escolher o CAP mais eficiente na remoção da substância de interesse. Os resultados dessas duas maneiras de caracterização do CAP foram comparados, a fim de verificar a melhor forma de estabelecer o CAP com maior eficiência adsortiva, conforme mostrado a seguir.

\section{Caracterização dos CAPS}

- Granulometria e número de iodo: os CAPs comercializados devem estar de acordo com os parâmetros estabelecidos pela norma EB-2133 (ASSOCIAÇÃO BRASILEIRA DE NORMAS TÉCNICAS, 1991C), conforme Tabela 2. Dentre eles, estão a granulometria e o número de iodo, que foram analisados para os cinco CAPs deste estudo. A Tabela 3 mostra os resultados obtidos para cada CAP e o resultado fornecido em laudo pela empresa fabricante.

A granulometria é utilizada para que seja conhecido o tamanho dos grãos do CA, uma vez que quanto menores forem os grãos, maior é a taxa de adsorção, pois o tamanho do adsorvente determina o tempo requerido para o transporte dentro dos poros, que são os locais em que ocorre a adsorção (SNOEYINK, 1990; DI BERNARDO; DANTAS, 2005). Já o número de iodo está relacionado com a adsorção de moléculas de pequeno peso molecular (DI BERNARDO; DANTAS, 2005), sendo usado como um índice representativo da quantidade de microporos presente na amostra de carvão (BRandāo; Silva, 2006).

Os resultados da granulometria mostraram que todos os CAPs estão de acordo com os valores mínimos para as peneiras n. 100 e $\mathrm{n}$. 200. No entanto, para a peneira n. 325, os CAPs MAD2, COCO e ANTRA apresentaram valores inferiores ao mínimo estabelecido. Já para o número de iodo, somente o CAP OSSO não apresentou o mínimo exigido. A empresa fabricante desse CAP alegou que, como a norma não é aplicada para CAP de origem animal, esses limites não devem ser considerados especificamente para esse CAP. 
Tabela 3 - Resultados de granulometria e número de iodo dos ensaios realizados e os fornecidos em laudo pelas empresas fabricantes

\begin{tabular}{|c|c|c|c|c|c|c|c|c|}
\hline \multirow{3}{*}{ CAP } & \multicolumn{4}{|c|}{ Fabricante } & \multicolumn{4}{|c|}{ Ensaios deste trabalho } \\
\hline & \multicolumn{3}{|c|}{$\begin{array}{c}\text { Granulometria } \\
\text { (\% em massa passante) }\end{array}$} & \multirow{2}{*}{$\begin{array}{l}\text { Número de iodo } \\
\left(\mathrm{mg} \mathrm{I}_{2} \cdot \mathrm{g}^{-1}\right)\end{array}$} & \multicolumn{3}{|c|}{$\begin{array}{c}\text { Granulometria } \\
\text { (\% em massa passante) }\end{array}$} & \multirow{2}{*}{$\begin{array}{l}\text { Número de iodo } \\
\left(\mathrm{mg} \mathrm{I}_{2} \cdot \mathrm{g}^{-1}\right)\end{array}$} \\
\hline & $\begin{array}{l}\text { Peneira } \\
\text { n. } 100\end{array}$ & $\begin{array}{l}\text { Peneira } \\
\text { n. } 200\end{array}$ & $\begin{array}{l}\text { Peneira } \\
\text { n. } 325\end{array}$ & & $\begin{array}{l}\text { Peneira } \\
\text { n. } 100\end{array}$ & $\begin{array}{l}\text { Peneira } \\
\text { n. } 200\end{array}$ & $\begin{array}{l}\text { Peneira } \\
\text { n. } 325\end{array}$ & \\
\hline MAD1 & * & * & 96,4 & 767 & 99,7 & 99,4 & 96,0 & 832 \\
\hline MAD2 & * & * & * & * & 99,5 & 97,1 & 85,7 & 863 \\
\hline COCO & * & * & 100 & 800 mín. & 99,9 & 96,1 & 89,6 & 921 \\
\hline Osso & 90 & 70 & 60 & $200 * *$ & 99,9 & 99,6 & 99,0 & 98 \\
\hline ANTRA & 99 mín. & 95 mín. & 90 mín. & 600 mín. & 99,9 & 98,2 & 77,1 & 619 \\
\hline
\end{tabular}

* dados não apresentados nos laudos; ** este é o valor indicado pelo fabricante para carvão de origem animal.

Tabela 4 - Área superficial e distribuição e volumes de poros das cinco amostras de CAP

\begin{tabular}{|c|c|c|c|c|c|}
\hline \multirow[b]{2}{*}{ CAP } & \multicolumn{4}{|c|}{ Volume $\left(\mathrm{cm}^{3} \cdot \mathrm{mg}^{-1}\right)$ - \% de volume de poros } & \multirow{2}{*}{$\begin{array}{l}\text { Área superficial } \\
(\text { BET })\left(m^{2} \cdot g^{-1}\right)\end{array}$} \\
\hline & $\begin{array}{l}\text { Microporos } \\
\text { secundários }\end{array}$ & $\begin{array}{l}\text { Microporos } \\
\text { total }\end{array}$ & Mesoporos & Macroporos & \\
\hline MAD1 & $0,0768-5$ & $1,4378-86$ & $0,2127-13$ & $0,0295-2$ & 782,3 \\
\hline MAD2 & $0,0841-6$ & $1,1464-78$ & $0,2842-19$ & $0,0414-3$ & 862 \\
\hline $\mathrm{COCO}$ & $0,1209-8$ & $1,2900-88$ & $0,1361-9$ & $0,0439-3$ & 857,4 \\
\hline Osso & $0,0136-4$ & $0,0920-27$ & $0,1821-51$ & $0,0761-22$ & 126,4 \\
\hline ANTRA & $0,0655-7$ & $0,7542-86$ & $0,0959-11$ & $0,0277-3$ & 611,2 \\
\hline
\end{tabular}

Os resultados das análises de granulometria e número de iodo assemelham-se aos fornecidos pelos fabricantes (Tabela 3). No entanto, em alguns casos, os dados fornecidos não foram completos (MAD1 e COCO) ou apenas foi expresso o mínimo estabelecido pela norma - e não os resultados efetivos da amostra de CAP (ANTRA). Todos admitem que o seu CAP atende aos limites mínimos para ambos os parâmetros. Em função disso, para o ensaio do número de iodo e também das isotermas, os CAPs que não atingiram 95\% passante na peneira n. 325 foram utilizados com a granulometria apresentada, pois as ETAs utilizam o CAP da maneira como este é recebido - sem nenhum tipo de prétratamento. Por isso, optou-se por não moer os CAPs. O CAP com maior número de iodo foi o COCO, indicando uma possível maior capacidade adsortiva em relação aos demais.

- Distribuição e volume de poros: estudo realizado por Donati et al (1994), no qual foram analisadas oito amostras de CAP, verificou que os carvões produzidos a partir da madeira apresentam os maiores volumes de microporos e mesoporos. Os resultados encontrados para as cinco amostras de CAP analisadas (Tabela 4) também mostraram que os CAPs de origem vegetal apresentam maior quantidade desses poros em relação aos demais, variando entre 78 a $88 \%$ do volume total de poros. Entretanto, o CAP de antracito (ANTRA) apresentou valores similares aos CAPs de madeira (MAD1 e MAD2) em relação ao volume de poros em todas as categorias. Estes valores estão de acordo com os valores encontrados por Brandão e Silva (2006).

O índice do número de iodo é utilizado como indicador do volume de microporos do carvão, sendo encontrada uma correlação significativa, $r=0,96(p<0,05)$, entre este índice e o volume de microporos.

\section{Isotermas de Freundlich}

Como a substância de interesse foi a microcistina, optou-se por trabalhar com a isoterma de Freundlich. A partir das curvas isotérmicas (Figura 1), foi possível calcular a capacidade máxima adsortiva $\left(q_{e, \text { maxx }}\right)$ de cada CAP, bem como as constantes $n$ e K que caracterizam o processo de adsorção (Tabela 5). A constante $n$ está relacionada com a força de ligação entre os agentes da adsorção, ou seja, entre o CAP e a microcistina. Já a constante $K$ relaciona-se com a capacidade do CAP em reter a microcistina (BRASIL; BRANDÃO, 2005; BRANDÃO; SILVA, 2006).

A constante $K$ é o parâmetro mais indicado para comparação entre os CAPs (BRASIL; BRANDÃO, 2005), pois foi obtida a partir do

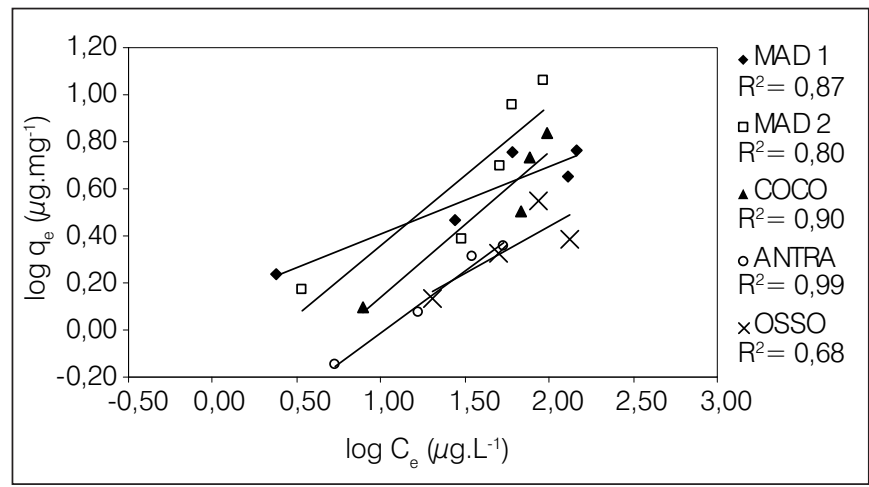

Figura 1 - Isotermas de Freundlich para as cinco amostras de CAP analisadas 
Tabela 5 - Capacidade máxima adsortiva $\left(q_{e, \text { máx }}\right)$ e constantes n e K obtidas a partir das isotermas de Freundlich para as cinco amostra de CAP

\begin{tabular}{lccc} 
CAP & $\begin{array}{c}\mathrm{q}_{\mathrm{e}, \operatorname{máx}^{-1}} \\
\left(\mu \mathrm{g} \cdot \mathrm{mg}^{-1}\right)\end{array}$ & $\begin{array}{c}K\left(\mu \mathrm{g} \cdot \mathrm{mg}^{-1}\right. \\
\left.\left(\mathrm{L} \cdot \mu \mathrm{g}^{-1}\right)^{1 / n}\right)\end{array}$ & $1 / n$ \\
\hline MAD1 & 5,82 & 1,32 & 0,288 \\
\hline MAD2 & 11,37 & 0,58 & 0,592 \\
COCO & 6,74 & 0,34 & 0,614 \\
OSSO & 3,31 & 0,43 & 0,531 \\
ANTRA & 2,66 & 0,28 & 0,403 \\
\hline
\end{tabular}

intervalo de dados testado. Sendo assim, o CAP MAD1 apresentou a maior capacidade adsortiva à microcistina $(K=1,32)$. Este mesmo carvão apresentou elevado valor de $n(3,47)$, correspondendo a uma maior irreversibilidade do processo de adsorção.

A análise de correlação entre a $q_{e, \text { máx }}$ e o volume de mesoporos não apresentou significância $(r=0,80 ; p<0,05)$, ao contrário do obtido por Donati et al (1994). Isso pode ser explicado pelo pequeno número de amostras avaliadas $(\mathrm{n}=5)$; porém, a correlação encontrada sugere que estes dois parâmetros estejam relacionados. Entretanto, segundo Lambert, Holmes e Hrudey (1996), Warhurst et al (1997) e Pendleton, Schumann e Wong (2001), para escolher o carvão que melhor remove microcistina, deve-se considerar que ela é uma molécula relativamente grande, com diâmetro estimado de 1,2 a 2,6 nm, além do volume de microporos secundários e mesoporos do CAP. Assim, observou-se uma correlação significativa, $r=0,96(p<0,05)$, entre $q_{e, \text { max }}$ e o volume de poros dessas categorias.

Não foi observada correlação significativa entre $q_{e, \text { máx }}$ e o índice do número de iodo e nem entre $\mathrm{q}_{e, \text { máx }}$ e a área superficial do CAP. Esses resultados estão de acordo com Donati et al (1994) e confirmam que o CAP utilizado para remoção de microcistina não deve ser escolhido a partir desses índices isolados. Devem ser consideradas as características do processo adsortivo à microcistina e as características relativas à distribuição e ao volume de poros (SNOEYINK, 1990; DI BERNARDO; DANTAS, 2005).

O intervalo de concentrações de CAP utilizado no ensaio não foi suficiente para reduzir a concentração inicial de toxina a $1 \mu \mathrm{g} . \mathrm{L}^{-1}$, conforme preconizado na Portaria n. 518 do Ministério da Saúde (BRASIL; 2004). No entanto, isso era esperado, pois, de acordo com o que foi mencionado anteriormente, a concentração inicial de microcistina utilizada nos experimentos é muito elevada, ocorrendo somente em raros eventos de florações de cianobactérias (MATTHIENSEN; YUNES; CODD, 1999). Esta concentração foi estabelecida para os ensaios laboratoriais com objetivo de avaliar a eficiência de remoção de microcistina pelos diferentes CAPs.

Assim, o decaimento logarítmico utilizando os residuais de microcistina (Figura 2), pôde ser utilizado para a determinação teórica e, para as mesmas condições experimentais, da concentração de CAP para atingir o residual de microcistina de $1 \mu \mathrm{g} . \mathrm{L}^{-1}$. O decaimento logarítmico proporciona uma análise direta das concentrações residuais de microcistina, permitindo estimar a dosagem de CAP que atenda um residual desejado (FERREIRA FILHO; 1996). Embora a própria equação da isoterma de Freundlich (Equação 1) permita calcular essa dosagem, de acordo com a concentração inicial de toxina e o residual esperado, optou-se por analisar o decaimento logarítmico, uma vez que, para utilizar a equação da isoterma, o tempo de contato adotado pressupõe ser o tempo de equilíbrio (o que pode não ter sido atingido em duas horas) e inexistência de competição com outros compostos que possam ser adsorvidos pelo CAP (como a toxina utilizada não era pura, mas resultante da lise celular, outros compostos intracelulares estavam presentes em solução) (SNOEYINK, 1990).

O ajuste ao decaimento logarítmico foi bom, ou seja, os valores de $\mathrm{R}^{2}$ não ficaram muito distantes de 1 , o que indica o ajuste ideal. $\mathrm{O}$ mesmo não foi verificado para as isotermas de Freundlich (Figura 1). Nos experimentos realizados não foi utilizada toxina purificada, mas o produto da lise de células de Microcystis aeruginosa diluído em água deionizada. Dessa forma, a água utilizada para a determinação das isotermas, além da microcistina, continha outros compostos orgânicos de origem intracelular. Esses compostos competem com a microcistina pelos sítios de adsorção no carvão ativado. Do ponto de vista prático, a situação estudada se aproxima mais de uma situação real, pois a água bruta captada de um lago eutrofizado com presença de cianobactérias tóxicas e que chega a uma ETA conterá, além de cianotoxinas, outros compostos orgânicos de origem intracelular liberados com a lise das células e compostos orgânicos de outras origens (BRANDÃO; SILVA, 2006).

A partir do modelo de decaimento logarítmico também foi possível obter uma equação geral (Equação 4) para o processo adsortivo de cada um dos CAPs, conforme Brasil (2004):

$C_{R}=C_{0} \cdot e^{-k C A P \cdot D}$

Equação 4

onde:

$\mathrm{C}_{\mathrm{R}}$ : concentração residual de microcistina;

$\mathrm{C}_{\mathrm{o}}$ : concentração inicial de microcistina;

kCAP: constante característica de sistema para determinado CAP;

D: dosagem do CAP.

Linearizando a Equação 4, tem-se:

$\ln \mathrm{C}_{\mathrm{R}}=\ln \mathrm{C}_{\mathrm{o}}-\mathrm{kCAP} \cdot \mathrm{D}$

Equação 5

Dessa forma, construindo um gráfico para cada CAP, com os valores de D (utilizados no experimento da isoterma de Freundlich) na abscissa e ln $C_{R}$ na ordenada (Figura 3), obtém-se a equação da reta e, a partir dela, encontra-se o valor de kCAP para cada um dos CAPs.

Assim, substituindo kCAP da Equação 4 pelo valor encontrado, tem-se a equação geral para cada CAP (Tabela 6). 


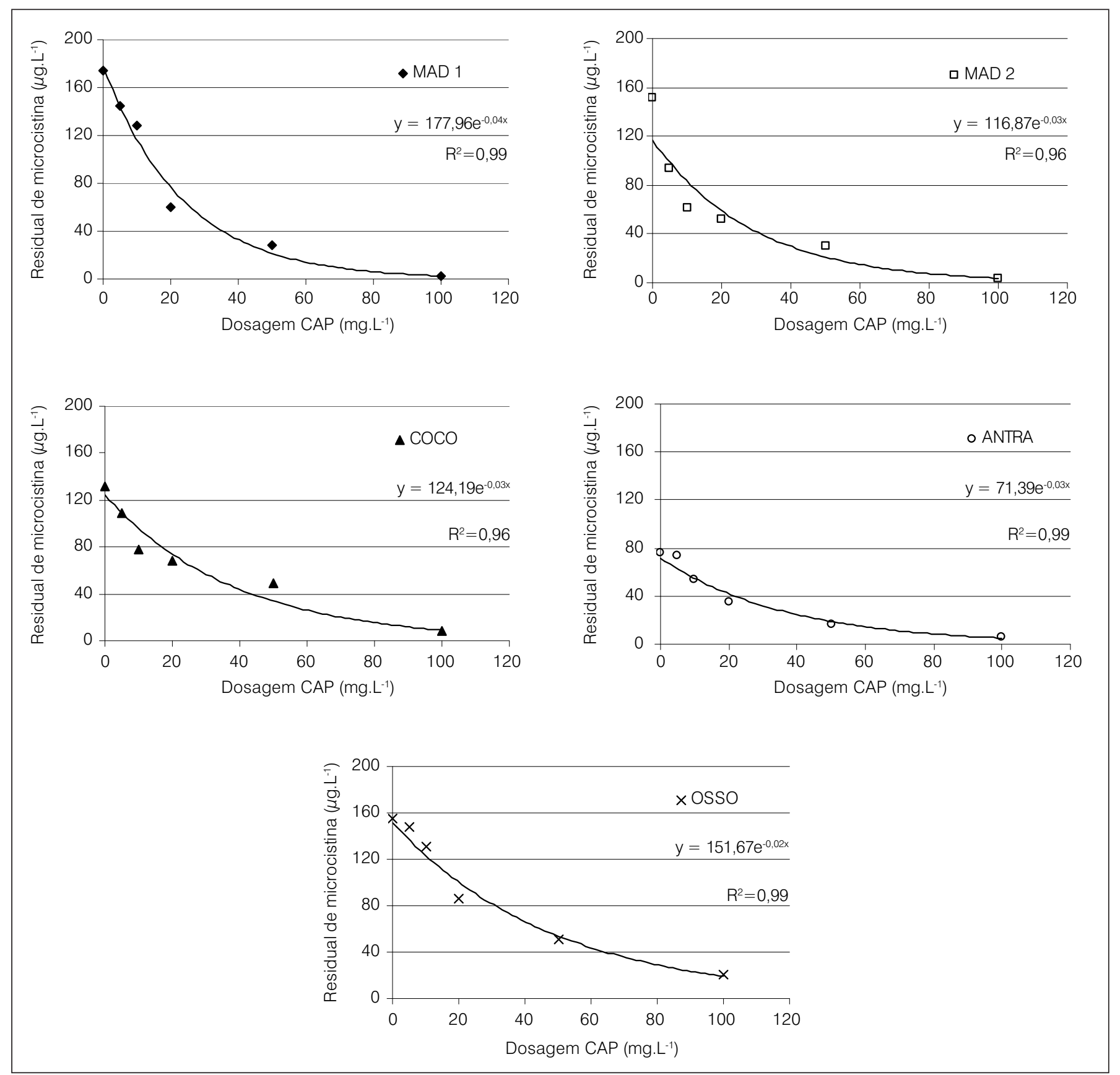

Figura 2 - Decaimento logarítmico dos residuais de microcistina para as cinco amostras de CAP analisadas

A partir das equações da Tabela 6, pode-se calcular a dosagem necessária de CAP para atingir $1 \mu \mathrm{g} . \mathrm{L}^{-1}$ de microcistina na água, de acordo com a concentração inicial da toxina. Porém, cabe ressaltar que esses valores não podem ser aplicados em águas naturais que abastecem as ETAs. Isso ocorre porque os experimentos foram realizados com água deionizada, não contendo compostos orgânicos competidores pelos sítios de adsorção dos CAPs, como ocorre na água bruta (PENDLETON; SCHUMANN; WONG, 2001). Assim, a concentração efetiva de CAP deve ser mais elevada, pois esses compostos orgânicos reduzem a eficiência de adsorção do CAP (DONATI et al, 1994; LAMBERT; HOLMES; HRUDEY, 1996; LEE; WALKER, 2006).

\section{Conclusões}

Com base na obtenção e na análise dos resultados, pode-se chegar às seguintes conclusões:

- o índice do número de iodo fornecido pelos fabricantes não é, isoladamente, um bom indicador da $\mathrm{q}_{e, \text { máx }}$ do CAP. Este índice, portanto, não deve ser utilizado individualmente para a escolha do CAP mais eficiente na remoção de microcistina (NG et al, 2002);

- a avaliação da capacidade adsortiva do CAP constitui uma etapa importante e necessária para a aquisição do CAP pelas ETAs. A capacidade adsortiva de um CAP, em relação à microcistina, é 


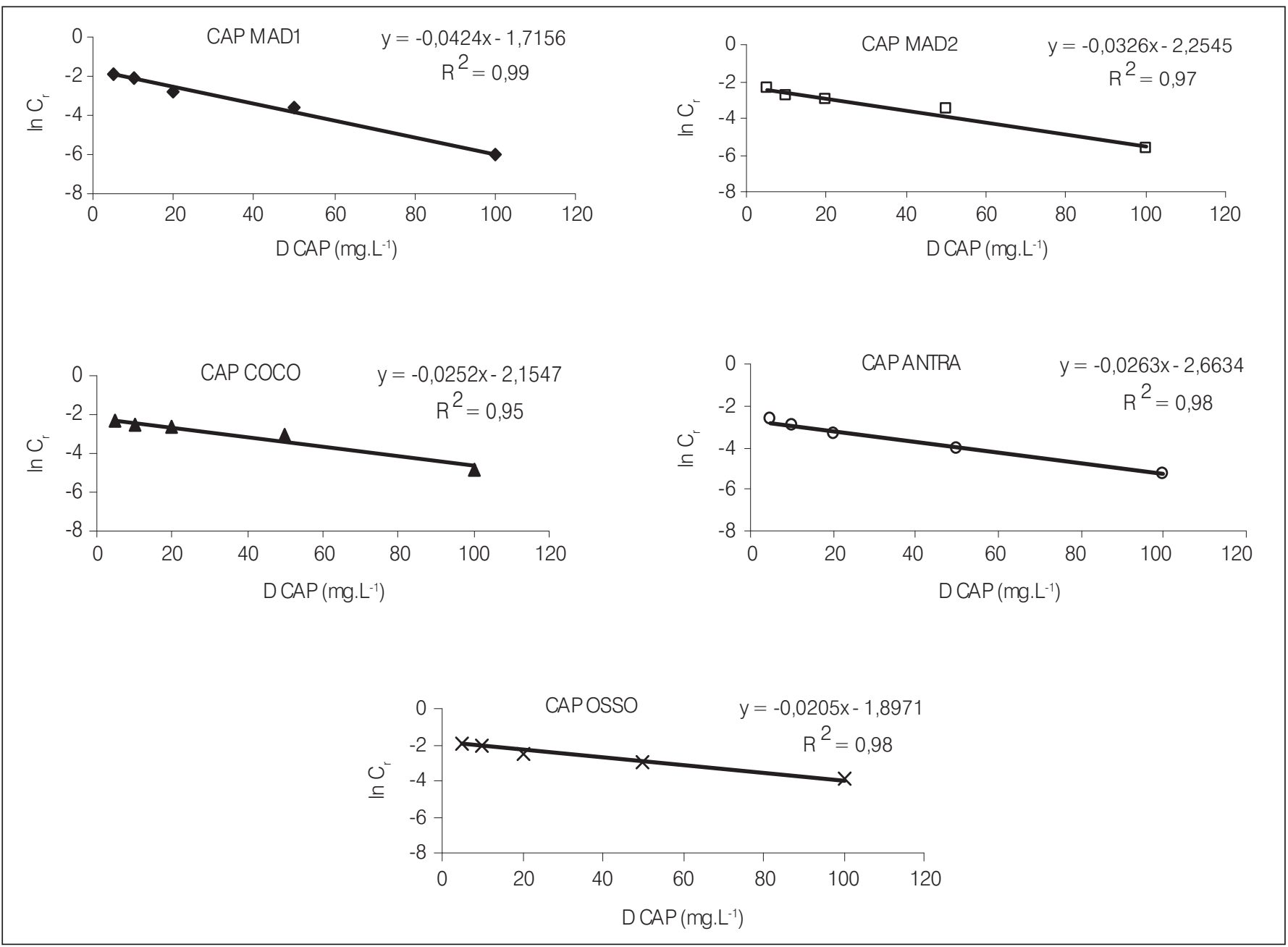

Figura 3 - Ajuste ao modelo de decaimento dos residuais de microcistina em relação à dosagem do CAP, para cada amostra estudada, e obtenção da constante kCAP

Tabela 6 - Equação geral para o processo adsortivo utilizando cinco amostras de CAP

$\begin{array}{llc}\text { CAP } & \text { Equação geral } & \text { Constante kCAP } \\ \text { MAD1 } & C_{R}=C_{O} \cdot e^{-0,0424 \cdot D} & 0,0424 \\ \text { MAD2 } & C_{R}=C_{O} \cdot e^{-0,0326 \cdot D} & 0,0326 \\ \text { COCO } & C_{R}=C_{O} \cdot e^{-0,0252 \cdot D} & 0,0252 \\ \text { OSSO } & C_{R}=C_{O} \cdot e^{-0,0205 \cdot D} & 0,0205 \\ \text { ANTRA } & C_{R}=C_{O} \cdot e^{-0,0263 \cdot D} & 0,0263\end{array}$

melhor avaliada pela isoterma de Freundlich. A capacidade adsortiva máxima $\left(q_{e, \text { max }}\right)$ só deve ser utilizada quando for possível calculá-la dentro do conjunto de dados experimentais; caso contrário, deve-se optar pela constante $K$ como parâmetro indicador do processo adsortivo do CAP. Os CAPs de madeira avaliados nesse estudo mostraram maior eficiência para remover a microcistina, em relação os demais CAPs, pois apresentaram os maiores valores de $K$ e $q_{e, \text { máx }}$ A adsorção da microcistina utilizando o CAP MAD1 tende a ser ainda mais eficiente, uma vez que a toxina mantém-se mais fortemente aderida ao CAP, em função da irreversibilidade do processo adsortivo, verificada por meio do elevado valor da constante $n$;

- também é importante avaliar o volume de microporos secundários e mesoporos do carvão, pois são parâmetros que influenciam na sua capacidade de remoção de microcistina;

- a partir do decaimento logarítmico dos residuais de microcistina, pôde-se calcular a dosagem necessária de CAP para atingir $1 \mu \mathrm{g} . \mathrm{L}^{-1}$ de microcistina na água. Porém, cabe ressaltar que esses valores não podem ser aplicados em águas naturais que abastecem as ETAs. Isso ocorre porque os experimentos foram realizados com água deionizada, não contendo compostos orgânicos competidores pelos sítios de adsorção dos CAPs, como ocorre na água bruta (PENDLETON; SCHUMANN; WONG, 2001). Assim, a concentração efetiva de CAP deve ser mais elevada, pois esses compostos orgânicos reduzem a eficiência de adsorção do CAP à microcistina (DONATI et al, 1994; LAMBERT; HOLMES; HRUDEY, 1996; LEE; WALKER, 2006). Assim, recomenda-se a realização dos mesmos experimentos apresentados neste estudo, porém, além da substância de interesse para remoção, deve ser utilizada a água bruta a ser tratada. 


\section{Agradecimentos}

Ao Conselho Nacional de Desenvolvimento Científico e Tecnológico (CNPq) e à Financiadora de Estudos e Projetos (Finep), pelos recursos destinados ao projeto Programa de Pesquisa em Saneamento Básico (Prosab), edital 4, tema 1, ao qual este trabalho esteve vinculado.

À Coordenação de Aperfeiçoamento de Pessoal de Nível Superior (Capes) pelo suporte financeiro concedido (bolsa de mestrado).

\section{Referências}

AMERICAN SOCIETY FOR TESTING AND MATERIALS. Standard practice for determination of adsorptive capacity of activated carbon by aqueous phase isotherm technique -D3860-98. In: AMERICAN SOCIETY FOR TESTING AND MATERIALS. Standards on activated carbon. Philadelphia, 2000. p. 47-49.

ASSOCIAÇÃO BRASILEIRA DE NORMAS TÉCNICAS. Carvão ativado pulverizado - Determinação granulométrica - MB-3412. Rio de Janeiro, 1991A.

Carvão ativado pulverizado - Determinação do número de iodo - MB-3410. Rio de Janeiro, 1991B.

Carvão ativado pulverizado - Especificação - EB-2133. Rio de Janeiro, 1991C.

AZEVEDO, S.M.F.O.; MAGALHÃES, V. Metodologia para quantificação de cianotoxinas. In: PÁDUA, V.L. (Org.). Contribuição ao estudo da remoção de cianobactérias e microcontaminantes orgânicos por meio de técnicas de tratamento de água para consumo humano. Rio de Janeiro: ABES, 2006. p. 467-503.

AZEVEDO, S.M.F.O. et al. First report of microcystins from a Brazilian isolate of the cyanobacteruim Microcystis aeruginosa. Journal of Applied Phycology, n. 6, p. 261-265, 1994.

BRANDÃO, C.C.S.; SILVA, A.S. Remoção de cianotoxinas por adsorção em carvão ativado. In: PÁDUA, V.L. (Org.). Contribuição ao estudo da remoção de cianobactérias e microcontaminantes orgânicos por meio de técnicas de tratamento de água para consumo humano. Rio de Janeiro: ABES, 2006. p. 415-465.

BRASIL. Ministério da Saúde. Portaria n.518, de 25 de março de 2004. Estabelece os procedimentos e responsabilidades relativos ao controle e vigilância da qualidade da água para consumo humano e seu padrão de potabilidade, e dá outras providências. Brasília, DF: Diário Oficial da União; 26 mar 2004; Seção 1, p. 266-270.

Ministério da Saúde/Fundação Nacional da Saúde. Cianobactérias tóxicas na água para consumo humano. Impactos na Saúde Pública e processos de remoção em água para consumo humano. Brasília, DF: Funasa/MS, 2003.

BRASIL, C.P. Avaliação da remoção de microcistina em água de abastecimento público por diferentes carvões ativados em pó produzidos no Brasil. 2004. 114 f. Dissertação (Mestrado em Tecnologia Ambiental e Recursos Hídricos) - Departamento de Engenharia Civil e Ambiental da UnB, Brasília, DF, 2004.

BRASIL, C.P.; BRANDÃO, C.C.S. Avaliação da remoção de microcistina em água de abastecimento público por diferentes carvões ativados em pó produzidos no Brasil. In: $23^{\circ}$ CONGRESSO BRASILEIRO DE ENGENHARIA
SANITÁRIAEAMBIENTAL, Anais..., Campo Grande: Associação Brasileira de Engenharia Sanitária e Ambiental - ABES, 2005.

CEBALLOS, B.S.O.; AZEVEDO, S.M.F.O.; BENDATE, M.M.A. Fundamentos biológicos e ecológicos relacionados as cianobactérias. In: PÁDUA V.L. (Org.). Contribuição ao estudo da remoção de cianobactérias e microcontaminantes orgânicos por meio de técnicas de tratamento de água para consumo humano. Rio de Janeiro: ABES, 2006. p. 23-81.

CHOW, C.W.K. et al. The impact of conventional water treatment processes on cell of the cyanobacterium Microcystis aeruginosa. Water Research, v. 33, n. 15, p. 3253-3262, 1999.

COELHO, E.R.C.; VAZZOLER, H. Capacidade de adsorção frente as isotermas de Langmuir e Freundlich para atrazina em materiais zeolíticos e carbonosos utilizados em tratamento de água na remoção de matéria orgânica natural e sintética. In: $23^{\circ}$ CONGRESSO BRASILEIRO DE ENGENHARIA SANITÁRIA E AMBIENTAL, Anais..., Campo Grande: Associação Brasileira de Engenharia Sanitária e Ambiental - ABES, 2005.

DI BERNARDO, L.; DANTAS, A.D.B. Métodos e técnicas de tratamento de água. 2. ed. São Carlos: Rima, 2005.

DONATI, C. et al. Microcystin-LR adsorption by powdered activated carbon. Water Research, v. 28, n. 8, p. 1735-1742, 1994

DRIKAS, M. et al. Using coagulation, flocculation and settling to remove toxic cyanobacteria. Journal AWWA, v. 93, n. 2, p. 100-111, fev. 2001

ESTEVES, F. Fundamentos de limnologia. 2. ed. Rio de Janeiro: Interciência, 1998.

FERREIRA FILHO, S.S. Otimização da aplicação do carvão ativado em pó no tratamento de água visando a redução de compostos orgânicos causadores de odor e sabor em águas de abastecimento. Engenharia Sanitária e Ambiental, v. 1, n. 4, p. 131-143, 1996.

HIMBERG, K. et al. The effect of Water Treatment Process on the removal of hepatotoxins form Microcystis and Oscillatoria cyanobacteria: a laboratory study. Water Research, v. 23, n. 8, p. 979-984, 1989.

HUSZAR, V.L.M. etal. Cyanoprokaryotes assemblages in eight productive tropical Brazilian waters. Hydrobiologia, n. 424, p. 67-77, 2000.

JOCHIMSEN, E.M. et al. Liver failure and death after exposure to microcystins at a hemodialysis center in Brazil. The New England Journal of Medicine, v. 338, n. 13, p. 873-878, 1998.

KURODA, E.K. et al. Caracterização e escolha do tipo de carvão ativado a ser empregado no tratamento de águas contendo microcistinas. In: $23^{\circ}$ CONGRESSOBRASILEIRODEENGENHARIASANITÁRIAEAMBIENTAL, 
Anais..., Campo Grande: Associação Brasileira de Engenharia Sanitária e Ambiental - ABES, 2005.

LAGOS, N. et al. The first evidence of paralytic shellfish toxins in the freshwater cyanobacterium Cylindrospermopsis raciborskii, isolated from Brazil. Toxicon, v. 37, p. 1359-1373, 1999.

LAMBERT, T.W.; HOLMES, C.F.B.; HRUDEY, S.E. Adsorption of microcystin-LR by activated carbon and removal in full scale water treatment. Water Research, v. 30, n. 6, p. 1411-1422, 1996.

LEE, J.; WALKER, H.W. Effect of process variables and natural organic matter on removal of microcystin-LR by PAC-UF. Environmental Science \& Technology, v. 40, n. 23, p. 7336-7342, 2006.

MATTHIENSEN, A.; YUNES, J.S.; CODD, G.A. Ocorrência, distribuição e toxicidade de cianobactérias no estuário da Lagoa dos Patos, RS. Revista Brasileira de Biologia, São Carlos, v. 59, n. 3, p. 361-376, 1999.

NG, C. et al. Freundlich adsorption isotherms of agricultural by-productbased powdered activated carbons in a geosmin-water system. Bioresource Technology, v. 85, n. 2, p. 131-135, 2002.
PENDLETON, P.; SCHUMANN, R.; WONG, S.H. Microcystin-LR adsorption by activated carbon. Journal of Colloid and Interface Science, n. 240, n. 1, p.1-8, 2001

SIVONEN, K.; JONES, G. Cyanobacterial toxins. In: CHORUS, I.; BARTRAM, J. (Edi.). Toxic cyanobacteria in water: a guide to their public health consequences, monitoring and management. London \& New York: World Health Organization, 1999.

SNOEYINK, V. Adsorption of organic compounds. In: LETTERMAN, R.D. Water quality \& treatment: a handbook of community water supplies. New York: American Water Works Association and McGraw-Hill, 1990. p. 781-867.

VIEIRA, J.M.S. et al. Toxic cyanobacteria and microcystin concentrations in a public water supply reservoir in the Brazilian Amazonia region. Toxicon, v. 45, n.7, p. 901-909, 2005.

WARHURST, A.M. et al. Adsorption of the cyanobacterial hepatotoxin microcystin-LR by a low-cost activated carbon from the seed husks of the pan-tropical tree, Moringa oleifera. The Science of the Total Environment, v. 207, n. 2-3, p. 207-211, 1997. 